\title{
Sambando no miudinho: a estética performativa das mulheres do Recôncavo Baiano
}

\author{
"Sambando no miudinho": The \\ performative aesthetics of women \\ from the Recôncavo Baiano
}

Clécia Maria Aquino de Queiroz ${ }^{1}$ https://orcid.org/0000-0002-4561-1927

\begin{abstract}
Resumo: Este trabalho analisa as configurações cênicas do samba de roda no Recôncavo Baiano, a partir das vozes e das performances das mulheres sambadeiras. Para perseguir tais objetivos, o estudo foi realizado com uma abordagem qualitativa, tendo como suporte os princípios da Etnocenologia. A análise das estéticas performativas do samba de roda do Recôncavo Baiano levou a compreensão de que elas não se resumem ao gesto, à dança ou à música. Elas são todo um complexo de percepção de si mesmo(a) e da(o) outra(o), onde o movimento, ludicidade, musicalidade e criatividade são conjugados juntos com a ambiência e relações de sociabilidade. O estudo rítmico do sapatear de algumas sambadeiras, com posterior transcrição para notação musical, apontou para a inexistência de um padrão único do passo conhecido como miudinho que difere de acordo com o estilo praticado pela comunidade de samba e com as percepções individuais das praticantes. A pesquisa ressalta ainda a importância e protagonismo das mulheres do samba de roda na organização dos eventos e na configuração dos seus procedimentos cênicos essenciais.
\end{abstract}

Palavras-Chave: Samba de roda; Corporeidade; Gênero

Abstract: This article analyzes the scenic configurations of the "samba de roda" in the Recôncavo Baiano having as reference the voices and performances of "sambadeira" women. In order to aim at these objectives, the study was carried out under a qualitative approach, based on the principles of Ethnocenology. The analysis of the performative aesthetics of the "samba de roda from the

\footnotetext{
1 Programa Multi-institucional e Multidisciplinar em Difusão do Conhecimento (UFBA) / Universidade Federal de Sergipe (UFS). E-mail: cleciaqueiroz@gmail.com
} 
Recôncavo Baiano has led to the understanding that they are not limited to gesture, dance or music itself. They are a complex system of self-perception and perception of the other, where movement, playfulness, musicality and creativity are conjugated along with the ambience and relations of sociability. The study of the rhythmic tap dance of some "sambadeiras", along with later transcription for musical notation, pointed to the lack of a single pattern of the tiny step known as "miudinho" that differs according to the style practiced by the samba community and to the individual perceptions of the samba practitioners. The research also highlights the importance and protagonism of the women of samba de roda in the organization of traditional memory, organization of events, as well as in the configuration of their essential scenic procedures.

Keywords: Samba de roda; Corporeality; Gender

\section{Introdução}

"Dona da Casa me dá licença, me dá seu salão para vadiar...." Assim começa um samba tradicional do Recôncavo Baiano, local de muitas cenas, cenários, histórias e memórias de milhões de africanas e africanos que entraram no Brasil como escravizados e escravizadas, mas que souberam, com criatividade, usar os corpos como local de preservação do conhecimento dos seus antepassados e terminaram por configurar o que hoje a gente reconhece como patrimônio imaterial do Brasil e Obra Prima da Humanidade: o samba de roda. Este artigo analisa a performance cênica das mulheres sambadeiras, aquelas que materializam nos corpos a música do samba de roda, traduzindo-a em movimentos sutis das cadeiras, giros e sapateios dos pés.

O trabalho foi realizado a partir de entrevistas com 12 sambadeiras de diferentes localidades do Recôncavo, além do convívio com outras oito mestras, participando de rodas de conversas realizadas pelo projeto "Circulando com as Mulheres do Samba de Roda" ${ }^{2}$, no qual participei como mediadora. A pesquisa foi feita com uma abordagem qualitativa, tendo como suporte os princípios da Etnocenologia (BIÃO, 1999; PRADIER, 1999), perspectiva teórica que tem como finalidade o estudo das práticas e os comportamentos humanos espetaculares (PCHEO), utilizando diversos recursos metodológicos como: pesquisa bibliográfica; documental; observação participante e colaborativa; entrevistas; registros sonoros e fotografias.

Peço licença, pois, a leitora e ao leitor para adentrar no terreno sutil de letras, símbolos,

\footnotetext{
${ }^{2}$ Idealizado por Rosildo Rosário e Luciana Barreto, o projeto circulou por nove cidade municípios do Recôncavo, e por Salvador, Rio de Janeiro, São Paulo e Jundiaí.
} 
representações e conhecimentos ancestrais e encontrar o sentido do verbo "vadiar", lembrando que o corpo é local por onde o samba de roda se expressa, expurga as dores e celebra a alegria da vida. E, nessa direção, vadiar para mim é, sobretudo, demonstrar a potência corporal para a diversão, para o compartilhamento com o outro, para o encontro com a ancestralidade presente na música, nas canções, nas vozes, nos instrumentos, na indumentária, no ritual cênico.

Neste estudo, parto do princípio de que o samba de roda não pode ser visto apenas como música ou como dança ou ainda puramente como uma prática social. Nada existe nele de forma isolada, tudo é parte de um todo. A pesquisadora de Trinidad e Tobago, Pearl Primus (2002), se refere à dança africana como uma arte que não deve ser vista de forma separada, mas, sim, parte de todo um complexo, sendo que a cerimônia em si é o complexo. A performance está, pois, atrelada a outros elementos que lhe conferem sentido e a uma religiosidade, na qual corpo e espírito estão articulados. Nesse sentido, o samba de roda guarda o caráter holístico da arte africana, no qual música, dança, indumentária, literatura e expressão cênica fazem parte de um todo inextrincável. O psíquico e o somático parecem estar em estreita associação, na qual o corpo responde dialogicamente com a música em performances individuais e coletivas.

Dentro do próprio fenômeno "samba de roda" a individualidade de expressão da sambadeira é única, não havendo, por exemplo, uma forma de tocar ou de dançar igual a outra. Cada indivíduo traz a sua singularidade na roda. Por outro lado, cada localidade, onde o samba é parte da vida comunitária das pessoas, tem práticas variantes com muitas coisas similares, nas especificidades na forma de tocar, no tipo de instrumento, de dividir o centro da roda, de pisar o solo no "miudinho". De modo que, ao olhar para o samba de roda, precisa-se estar atento ao que há de singular no todo. Ao mesmo tempo em que ele é uma expressão integral, no sentido em que envolve a articulação de várias expressões artísticas, não é homogêneo. De forma reducionista foi agrupado pelo Instituto do Patrimônio Histórico e Artístico Nacional (Iphan) em duas (ou até mesmo três) modalidades: samba chula, corrido (e barravento). Porém, a depender da comunidade em que ele se apresenta, os seus praticantes não reconhecem o que fazem por esses nomes. De modo que poderíamos mesmo falar de samba(s) de roda.

Dentro dos limites estabelecidos por sua complexidade, voltei o meu olhar mais diretamente para a vivência prática das mulheres, ou seja, para a performance dos corpos em cena, que pouca ênfase tem sido dada pelos estudiosos dessa expressão cultural. Ao analisar a performance das sambadeiras, encontramos diferentes funções e papéis que exercem na(s) roda(s) de samba, onde geralmente assumem a dança e não ocupam o lugar central da produção musical, atendo-se a responder ao coro, bater palmas ou a tocar o prato-e-faca, sendo que algumas poucas mulheres furam essa tradição e assumem algum outro instrumento percussivo 
e o solo no canto. Este trabalho buscou entender o significado de relações que são estabelecidas entre homens e mulheres, que assumem funções diversas dentro da prática que executam e que perpassam por relações de poder. Então, estamos falando de diferenças nas relações estabelecidas pelo sexo, que, de acordo com a historiadora Joan Scott (1990), é a primeira forma de dar significado às relações de poder. Estamos, pois, falando de questões de gênero. A pesquisa buscou também analisar a corporeidade e o movimento das mulheres dentro da roda de samba. E é sobre esses dois temas que tratarei nas próximas sessões.

\section{A mulher no samba de roda}

As sambadeiras do Recôncavo Baiano são negras. A luta histórica que o feminismo vem traçando desde a segunda metade da década de 1960 contra o domínio do homem sobre a mulher terminou revelando diferenças dentro da diferença, sendo uma delas a experiência de mulheres negras, que é diversa das não negras. Desde então, gênero e raça são duas categorias com as quais a existência da mulher negra tem sido estudada. Para nós, negras, raça e gênero se interseccionam, implicando em formas diversas de opressão não experimentadas por outras mulheres não negras ${ }^{3}$. Atenta à interligação dessas categorias, Vânia Silva Bonfim (2009) pondera que, no Brasil, o marco da inextrincabilidade de raça e gênero, para compreender a subalternização, estereotipação, discriminação e exclusão das mulheres negras, é a escravidão, onde as relações sociais foram reelaboradas. Bonfim menciona a autonomia das mulheres africanas, o papel de gestora econômica e a centralidade que exerciam na África nos séculos XV e XVI. Todo esse arcabouço civilizatório, que inclui as concepções e os valores, foi transplantado junto com elas nas suas estruturas cognitivas. Dentro do que era possível fazer, em meio a resistências e negociações na estrutura de organização colonial, aproveitando os vagos espaços que the foram dados e abrindo outros por elas mesmas, conseguiram reelaborar suas práticas religiosas as danças, as músicas, os modos de vestir e de falar. Bonfim sustenta que, para reconstruir esse marco de dominação, as mulheres negras usaram duas ferramentas contrastantes: o mundo civilizatório que trouxe em si da África e o mundo civilizatório que se impôs sobre elas no Brasil. (BOMFIM, 2009)

\footnotetext{
${ }^{3} \mathrm{O}$ termo intersecionalidade utilizado para designar as diferenças entre as diferenças foi sugerido pela filósofa negra estadunidense Kimberlé Crenshaw, o que auxiliou muito na identificação de diferentes formas de opressão vividas por mulheres. (GOMES; ROSA, 2014)
} 
No Recôncavo, a experiência vivida pelas sambadeiras - sobretudo por aquelas que residem em localidades onde atitudes classistas e o racismo são mais exacerbados e evidentes - é de enfrentamentos cotidianos, quase sempre dolorosos. A luta que travam a cada dia, como pontua Carneiro (2011), depende não apenas da capacidade de superação da hegemonia do homem sobre a mulher, mas de superar as ideologias racistas dominantes nas suas comunidades. A preservação e continuidade do samba de roda têm sido "negociadas" e mantidas através de muita resistência.

No que concerne à performance cênica/musical do samba de roda, as considerações feministas na musicologia de Susan McClary (1991) auxiliaram-me a refletir sobre questões de gênero dentro delas. Ela aborda a invisibilidade do feminino na música ocidental, fruto de diversas estratégias para restringir o acesso das mulheres à produção musical. Argumenta que os musicistas masculinos em muitos períodos históricos foram acusados de afeminados, tendo a subjetividade e o corpo relegados ao domínio do "feminino". Passaram então a apoiar a dimensão "racional" e adotaram a objetividade, universalidade e transcendência, proibindo a participação feminina. Em contrapartida, as mulheres, ao enveredarem pelos caminhos da composição ou da execução musical, seguiram o "esperado" pela ordem social, buscando músicas dentro dos padrões femininos.

Quanto às questões acerca da produção musical estarem centradas na figura masculina, Rodrigo Gomes (2011), ao analisar as primeiras três décadas do samba no Rio de Janeiro, encontra no livro "Corpo e Ancestralidade", de Inaicyra Falcão (2006), a razão para a percussão do samba carioca estar nas mãos dos homens. Inacyra descreve um mito Yorubá, que atribui a uma mulher, Ayántoke, chamada de Ayán, a criação do tambor Batá, presente do culto dos Egunguns. Ela teria colocado tiras de pele de um veado, que Ihe foram dadas por Exú numa floresta, sobre um pedaço de madeira oca, e ao tocar o instrumento criado, encantou a todos, incluindo Xangô, que a tornou sua esposa e com ela teve um filho, Aseorogi. A ele ensinou a arte de construir e tocar o tambor, cuja execução ficou restrita somente aos homens. Gomes atribui a esse mito uma provável razão para os tambores serem tocados somente pelos homens na maioria dos terreiros afro-brasileiros. Ele comenta que outros mitos, nos quais os instrumentos são criados/tocados pelas mulheres e depois usados somente pelos homens, são comuns entre os indígenas da região da Amazônia e que é bem provável que esse tipo de mitologia tenha influenciado o inconsciente coletivo da música popular brasileira, que tem o samba como um dos seus maiores expoentes (GOMES, 2011).

Essas análises de McClary (1991) e Gomes (2011) serviram-me, sobretudo, como uma provocação, um alerta para analisar o papel e a importância das mulheres no fazer musical do 
samba, o que me fez perceber que não se restringe apenas a tocar alguns poucos instrumentos percussivos (prato-e-faca, tabuinhas), mas que avança para relações que dão sentido à própria existência da música, através do diálogo corporal que estabelece com os tocadores, sendo mesmo, em alguns estilos de "samba de parada", regente do momento em que os sambadores retornam a cantar, uma vez que o momento da dança deve ser respeitado e não deve haver canto.

Percebo, entretanto, que ainda que as mulheres assumam papéis determinantes na roda, as questões de gênero se acentuam no acesso às linguagens musical e coreográfica, tanto na execução como no aprendizado. Esse acesso, que em determinadas localidades é bem demarcado, tem sido flexibilizado nos dias atuais, uma vez que certos procedimentos estabelecidos por diferença de sexo têm sido questionados pelos próprios praticantes do samba. Contudo, as funções musicais são ainda exercidas majoritariamente pelos homens e as coreográficas, pelas mulheres.

Saindo da esfera cênica, as mulheres tradicionalmente sempre assumiram a organização dos eventos, o preparo da comida, do vestuário, uma extensão do que elas fazem nos seus cotidianos, que incluem os cuidados com os filhos e gerenciamento das atividades orçamentárias. Diferentes das mulheres mais abastadas economicamente, elas sempre precisaram gerir suas próprias vidas, ainda que em condições desiguais, uma vez que não puderam se instruir, sendo boa parte delas iletradas.

Relacionando esse protagonismo com o samba de roda, Francimária Gomes e Laila Rosa (2014) ponderam que a transmissão dos saberes da dança e da música, para além de salvaguardarem a memória das tradições populares tem chamado atenção para as subjetividades, permitindo o registro do papel das mulheres antes invisível. Concordando com a autora, percebo que ainda que as práticas no samba de roda sejam desqualificadas pelas elites classistas e racistas de suas comunidades, as sambadeiras persistem, resistem e, por meio delas, têm revertido o foco dos holofotes de pesquisadores, turistas, artistas para seus trabalhos, que de certa maneira neutralizam alguns comportamentos negativos voltados para elas.

\section{O corpo da sambadeira na roda do samba}

O corpo é central no samba de roda. É através dele que a música encontra sua expressão física, material. E essa expressão ocorre no espaço ancestral do samba, que é a roda. 
Cabeça, busto, braços, mãos, bunda, pernas, pés e mãos são letras que combinadas constroem a gramática dos gestos que se tornam palavras escritas no corpo. Vestido com saia volumosa, que ajuda a pintar com traços fugazes o ambiente, o corpo ali discorre a sua "oralitura"4; revela tradições transmitidas e percebidas oral e visualmente. É na roda que o solo recebe o sapateado de uma única pessoa que do seu centro se ocupa. É lá que o corpo faz o invisível visível. Onde a ancestralidade faz o uno se tornar duplo, dando sentido ao que D. Zélia do Prato diz: "Eu nunca sambo sozinha. Ela [lansã] não sai de junto de mim $^{\prime \prime}$. Também é nesse espaço que as vozes dos sambadores ecoam cantigas que preenchem lacunas do passado e reintegra-o no presente. Os dedos desvelam histórias escondidas nas cordas do "machete" ${ }^{6}$; as mãos constroem pontes entre o individual e o coletivo no braço do violão e no couro dos pandeiros. Na roda, como pontua Sabino e Lody (2011, p.20), retoma-se "a unidade cósmica, aproximando e possibilitando importantes rituais de sociabilidade e também de inclusão, de pertencimento a um grupo, a uma sociedade, a um povo".

A roda do samba não é somente um espaço físico. É um espaço vivo, dinâmico, formado por pessoas que não estão estáticas como se paredes fossem; ao contrário, são como uma "estrutura" movente, que atua cantando, batendo palmas, por vezes esfregando a mão uma na outra, nos momentos da "chula", por exemplo, em que se deve escutar os cantadores. A roda se modifica com a saída da sambadeira para o seu sapateado e volta a ser alterada com o seu retorno, após ter distribuído o seu encanto entre os presentes. E depois, segue se renovando com novas saídas e retornos, diminuindo e aumentado, no caso dos "corridos", estilo de samba onde mais de uma pessoa ocupa o centro.

Esta sessão volta-se para a estética performativa das mulheres que ocorrem dentro da roda. E para iniciar essa discussão, chamo atenção para uma cena que filmei de uma apresentação do grupo Samba Suerdieck, durante os festejos de Nossa Senhora da Boa Morte em agosto de 2018, em Cachoeira, onde D. Dalva, matriarca do grupo entra na roda amparada pela sambadeira D. Ana Macedo e no momento em que dá início à apresentação do grupo, titubeia e quase cai. Sentindo naquele dia dores no joelho que lhe impossibilitavam de sapatear do jeito que sempre fez, ainda assim ela não abriu mão de fazer a abertura do evento, tamanho o amor pelo que faz e respeito pela multidão que estava ali principalmente para vê-la. Aos 90

\footnotetext{
${ }^{4}$ Alusão ao termo "oralitura", empregado por Leda Martins (1997) ao se referir aos atos de fala e de performance dos congadeiros do Congado do Reinado do Jatobá (MG), para matizar a inscrição das formas próprias da oralidade africana naqueles sujeitos.

${ }^{5}$ Zélia Maria Paiva Souza, sambadeira de São Braz, conhecida como D. Zelina ou D. Zélia do Prato. Entrevista realizada em 27 de julho de 2018.

${ }^{6}$ Referência à "viola de machete" utilizada no samba chula.
} 
anos, na ocasião, o desgaste natural de suas articulações se agrava pela frequência e volume de trabalho com o samba de roda e outras manifestações populares que vem promovendo há mais de 60 anos Valho-me agora desse exemplo para iniciar uma reflexão sobre o corpo no samba de roda.

Analisando o movimento nas atitudes corporais, Laban $(1978)^{7}$ percebeu a existência de quatro componentes inerentes a ele, aos quais denominou de "fatores do movimento", e estruturou-os conceitualmente de forma muito abrangente: fluência, espaço, peso e tempo. De acordo com a pesquisadora do legado de Laban, Lenira Rengel (2008), o agente, ou seja, aquele que se move se relaciona com os fatores de movimento de uma forma integral, uma vez que eles pertencem à própria natureza do existir. Nessa direção, se pensarmos na "dança" do samba de roda a partir desses fatores, enquanto o chão é desenhado pelos deslocamentos percussivos dos pés que simultaneamente realizam claves rítmicas em linhas retas horizontais, verticais ou circulares, os movimentos dos braços, pernas, torço e cabeça preenchem, dilatam, redefinem e organizam o espaço bidimensional ou tridimensionalmente de acordo com a duração, velocidade e amplitude dos movimentos. Aqui o fator tempo se sobressai, por ser a música um elemento fundamental para o sapateado das sambadeiras, que a ela está diretamente relacionado. O ritmo é determinante e tem uma métrica e contra métrica que naturalmente estão implicados com o tempo.

Por sua vez, a coreógrafa e pesquisadora Welsh-Asante (2002) chama atenção para a relação das danças africanas com a ancestralidade e com a terra, que é provedora e benevolente. O samba guarda em si essa mesma herança e as sambadeiras flexionam os joelhos aproximandose da terra e utilizam movimentos na parte inferior do tronco e nos quadris, com os pés pressionando o solo. Isso faz com que o fator peso ganhe muita evidência, sobretudo com uma qualidade mais firme nos movimentos. E estes, por sua vez, fluem de forma mais libertada ou controlada, a depender da sambadeira ou sambador.

Sabemos que o corpo humano, para se colocar de pé, ou seja, conquistar a verticalidade, precisa lutar contra a força da gravidade, o que significa fazer uma força idêntica em duas direções: uma para cima e outra para baixo. Se não atentamos para o que isso significa, quando adultos, basta olhar o desenvolver de uma criança para perceber o tempo necessário

\footnotetext{
${ }^{7}$ O pesquisador e coreógrafo Rudolf Laban observou que o movimento age como uma grande orquestra, na qual várias seções se relacionam entre si. E para realizar uma ação, uma parte do corpo pode agir como um "solista" ou várias partes podem ser detonadoras da ação e as outras acompanharem o movimento. Mas o corpo é uma unidade e qualquer ação de uma determinada parte dele precisa ser compreendida em relação ao todo, que será sempre afetado, seja com uma participação harmoniosa ou por meio de uma contraposição deliberada e até mesmo por uma pausa. (LABAN, 1978)
} 
para que os músculos e ligamentos a possibilitem vencer essa luta e encontrar o equilíbrio para ficar ereta. Em realidade, ela vai construindo ao longo dos meses sua técnica própria cotidiana para ficar de pé, ereta, equilibrar-se e também andar.

Para realizar o(s) miudinho(s), há uma alteração da técnica cotidiana de andar, uma vez que a sambadeira samba geralmente levantando minimamente a planta dos pés do chão. Com os pés num formato de um " $v$ " fechado, próximo do paralelo, ela parte de uma posição simétrica do corpo, para em seguida alterná-la para uma outra assimétrica, mexendo sempre com os quadris. Enquanto avança no espaço, faz os pés pressionarem o chão, transferindo o peso do corpo de uma perna para outra num curto intervalo de tempo. Se pensarmos esse intervalo em termos de pulsações musicais, numa única pulsação há três ou quatro transferências de peso, geralmente alternando o peso do metatarso para o calcanhar e para o pé inteiro. Isso faz com que o centro de gravidade do corpo se desloque constantemente e, como consequência, o equilíbrio é alterado. No samba de roda, o deslocamento do eixo do corpo em relação à gravidade, ocorre com frequentes trocas entre um pé e outro, mas o deslocamento é pequeno, o que não exige uma ação muscular muito grande para manter o corpo em equilíbrio. Mas para realizar os sapateados miúdos do samba, é preciso dobrar levemente os joelhos. E essa flexão, junto com a troca de apoio constante entre os pés, rebaixa o centro de gravidade e facilita o remexer dos quadris. Contudo, o ato do sapatear resulta em uma pressão da coluna vertebral - e então do corpo todo, na direção do solo; todo o peso da parte superior do corpo fica assentado sobre a articulação dos joelhos. Isso significa uma grande oposição de diferentes tensões entre as partes superior e inferior do corpo e é necessário que os músculos em ação tomem o lugar dos ligamentos para que a dança ocorra. Se não há um preparo muscular para isso, a atividade ao longo dos anos pode provocar um desgaste, sobretudo na articulação dos joelhos. Isso talvez explique o porquê das sambadeiras mais idosas sentirem dores "nas juntas", como costumam dizer, e tenham dificuldade de realizar o samba com a mesma destreza de outrora, como vimos na cena "capturada" por mim em Cachoeira. Dificuldade essa agravada pelo fato do corpo no samba estar em situação de equilíbrio permanente instável, embora quase imperceptível, e esse equilíbrio despende muita energia.

Domenici (2011) chama atenção para a relação entre as atividades do samba e as do dia a dia das sambadeiras, que terminam por fazer com que o corpo adquira o que Barba e Savarese (2012) chamam de técnicas extra-cotidianas. E entre estas, menciona a de equilibrar coisas em cima da cabeça, como bacias de louça ou de pratos. Ela comenta ainda que algumas sambadeiras dançam naquela região equilibrando uma garrafa cheia na cabeça. (DOMENICl, 2011). Evidentemente, para isso, o corpo faz diversos ajustes musculares, sobretudo quando o 
que se equilibra é algo mais pesado como faz D. Rita da Barquinha (Bom Jesus, Saubara), que equilibra uma miniatura de barca que pesa $7,5 \mathrm{~kg}$. Para que o corpo se mantenha em equilíbrio, é necessário que faça uma força contrária e igual à da gravidade, além de um certo deslocamento para mantê-lo na vertical, que passa pelo centro de gravidade e os pés, que são sua base de apoio. E é um desafio conseguir essa organização de forças contrárias e ainda sapatear e girar com passos miúdos e giros.

Se de um lado no(s) miudinho(s) o deslocamento entre um pé e outro não é grande, algumas sambadeiras agregam a esse passo outros tipos de sapateios, a exemplo de D. Santinha, do Distrito de Acupe (Santo Amaro) e D. Cadu, de Coqueiros (Maragogipe). A primeira, após percorrer a roda no miudinho, utiliza um súbito contratempo que separa largamente os pés do solo, colocando a perna esquerda atrás e a direita na frente, passando todo o peso do corpo, de forma firme, para a perna de trás, que tem o joelho fletido. Ela, então, retoma o miudinho, sacode os ombros, gira e por vezes repete essa atitude que geralmente surpreende o espectador.

Por outro lado, D. Cadu, após realizar um sapateado miúdo por alguns segundos, executa também, contra a métrica do ritmo, um salto baixo de um pé para dois pés, com um grande deslocamento no espaço, mas mantendo a coluna dentro do eixo de gravidade. A sensação é de que ela realiza pequenos voos para cima e aterrissa no lado direito ou esquerdo. Em seguida, retoma o seu miudinho, gira, para novamente realizar essa atitude cênica - que ela diz ter aprendido observando os caboclos nos terreiros de candomblé - e que tanto impressiona as plateias, especialmente por ter ela 98 anos de idade.

Tanto D. Santinha como D. Cadu, ao realizarem esses movimentos (ou atitudes cênicas) que provocam surpresa nos que as assistem, fazem um grande deslocamento do corpo em relação à linha da gravidade. Saem de uma posição simétrica repentinamente para outra assimétrica, dando a impressão de que vão cair. A mudança do "equilíbrio em ação" delas é feita com total domínio, provocando o que Barba (2012, p. 97) chama de "drama elementar": “a oposição das diferentes tensões no corpo do ator é percebida cinestesicamente pelo espectador como um conflito entre forças elementares". E a percepção desse conflito, da dificuldade de realização do movimento, é o que geralmente entusiasma as plateias ao verem a performance dessas duas sambadeiras. Barba observa ainda que, para passar de um equilíbrio de mínimo esforço (equilíbrio precário) para outro onde seja visível as forças contrárias que operam no corpo, é necessário que esse equilíbrio se torne dinâmico, o que vai exigir mais da ação dos músculos. Para ele, o ator (ou performer) que não possui esse domínio não é vivo em cena.

O corpo se equilibra no espaço. E de acordo com Rengel (2008), o espaço significa 
atenção, comunicação. Por exemplo, o modo como algumas sambadeiras orientam o olhar no espaço pode ser revelador de uma dificuldade na comunicação. Nas diversas apresentações observadas na pesquisa de campo ou em vídeos/documentários, percebi que os olhos de muitas delas, sobretudo as menos experientes, se orientam para baixo, para os próprios pés. Esse costume de manter o olhar baixo, que causa uma sensação de permanência no mundo interior, envolve fatores emocionais, históricos e comunitários e é necessária uma prática constante para abandonar o apoio no solo e tornar-se mais flexível. Contudo, as sambadeiras mais acostumadas com apresentações em eventos públicos comunicam-se através dos olhos com os presentes, usando o espaço de forma multifocada, ou seja, mais flexível, ou ainda, mais tridimensional. Elas não estão focadas em um determinado ponto (nos pés, por exemplo), mas ligadas ao mesmo tempo na música, nas outras pessoas da roda, embora, em determinados momentos, foquem no violeiro, no tocador de pandeiro. No entanto, o fazem com o espaço direto, ou seja, com a atenção inteiramente (e propositalmente) voltada para eles.

Em termos dos deslocamentos no espaço físico, o corpo geralmente se coloca num plano alto, comumente com uma atitude altiva, algumas vezes com o tronco um pouco voltado para frente, podendo às vezes atingir o plano médio nos giros ou em algum "contratempo", como os descritos acima nas performances de D. Santinha ou D. Cadu. Os caminhos percorridos são geralmente curvos, uma vez que a dança é realizada num espaço circular, e no sentido antihorário, mas também acontecem em linha reta, na maioria das vezes quando se vai ocupar o centro da roda. Os sapateados, por sua vez, alternam-se nas direções indo para trás, para frente, esquerda frente ${ }^{8}$. Nos giros, esses deslocamentos são feitos geralmente em sentido anti-horário em torno do próprio eixo do corpo, mas algumas sambadeiras, como D. Rita da Barquinha, fazem os seus volteios nos dois sentidos.

A posição dos braços no samba de roda varia também de acordo com o estilo e a localidade na qual a sambadeira está inserida. Observei em grupos de São Francisco do Conde, Terra Nova, Cachoeira, Acupe, São Braz que eles permanecem baixos, ao longo do corpo, às vezes completamente relaxados e outras, um pouco flexionados. Neste último caso, muitas vezes, com as mãos segurando as saias. É muito comum ver mulheres também nessa posição, mesmo quando dançam sem a saia, pois o costume de segurá-la faz com que os dedos façam a menção de agir como se ela ali estivesse. Também é corrente ver nessa mesma posição

\footnotetext{
${ }^{8}$ Acerca dessas direções, Amoroso $(2009,2017)$ observou os sambas de Cachoeira e São Félix e transcreveuas, na sua tese de doutorado, para um diagrama que criou a partir de um exercício prático que propôs. Ao lado da explicação escrita da autora, que agrega explanações sobre a distribuição do peso do corpo nos pés, o leitor consegue visualizar os caminhos percorridos pela sambadeira a partir do diagrama.
} 
movimentos nos braços e no tronco advindos de experiências corporais das danças dos cultos religiosos afro-brasileiros, não apenas entre aquelas praticantes dessas religiões, como também entre as que aprenderam a sambar na convivência com mulheres que frequentam os espaços dos terreiros de candomblé.

Ainda sobre a posição dos braços, Mestre Milton Primo (2018), sambador e violeiro de São Francisco do Conde, comenta que no samba chula

\begin{abstract}
(...) geralmente, não se solta os braços, o que prevalece é as cadeiras mexendo, e o pé ligeiramente saindo do chão, naqueles movimentos miúdos, faz parte também do ritual. Geralmente [não solta os braços], porque muitas sambadeiras, e eu acho também bonito é o arremate, muitas delas não rodopiam, aí sim, vai ter que dar. D. Dete, D. Luiza, D Lindaura, poxa, é bonito ver.
\end{abstract}

Chamo atenção para a relação música e corpo, que estabelecem um diálogo no samba de roda, dando sentido e razão para que os sapateados ou passos ocorram. Seguramente uma herança africana, como podemos deduzir das palavras de Ajayi (1998, p. 35), ao se referir aos eventos de dança dos povos iorubás: "Any Yoruba dance event is actually a dialogue between the music and the body; sometimes the music is dominant, at other times the body gestures dictate the pace, but both are inextricably tied to the main content of the event." ${ }^{\prime 9}$

Se os ritmos percutidos pelas mãos no pandeiro, na viola ou violão, assim como as linhas melódicas destes dois últimos são estímulos motrizes para a sambadeira ou para o sambador, as letras das cantigas não estão intimamente relacionadas com o sapateado, como no caso do pagode baiano, por exemplo, em que cada palavra proferida por um cantor se reverte num gesto coreográfico. O "samba no pé" é improviso que tem o sapateado como base, mas geralmente não há uma sequência de passos, como bem nos lembra Döring (2016). A sambadeira (ou o sambador) constrói sua própria "partitura" improvisada de movimentos, relacionando-se com o ritmo e improviso dos instrumentistas.

Analisando o samba de roda observo que as sambadeiras (e sambadores) ${ }^{10}$ possuem

\footnotetext{
${ }^{9}$ Qualquer evento de dança iorubá é na verdade um diálogo entre a música e o corpo; às vezes a música é dominante, outras vezes os gestos corporais ditam o ritmo, mas ambos estão inextricavelmente ligados ao conteúdo principal do evento. (Tradução nossa)

${ }^{10}$ Coloco aqui os sambadores entre parêntesis, por serem as mulheres que geralmente sambam na roda. Mas os homens também sambam e há entre os mais antigos exímios sambadores. Nesses casos, geralmente realizam um outro tipo de sapateado diferente do miudinho, que mais se assemelha ao samba de caboclo.
} 
uma base do seu próprio sapateado, que executam mais ou menos da mesma maneira, nas diversas apresentações. Porém, esse sapateado vai sofrer pequenas variações, diferentes acentos e alternâncias de tempo a partir das chamadas dos instrumentos e de como eles aguçam suas percepções. Vai variar também de acordo com as pessoas presentes na roda, que respondem ao coro e emanam uma quantidade maior ou menor de energia. Energia essa que influirá na da própria pessoa que está no centro da roda e das atenções e que retornará provocando diferentes velocidades e cores de movimentos, levados por um fluxo orgânico.

A performance das sambadeiras, portanto, não é fruto apenas de uma mecânica do corpo. Vai muito além disso. É marcada também por emoção, pela fluência, pelo desejo de realizar, de se comunicar com o outro, de extravasar. O que leva, por exemplo, D. Dalva, citada no início desta sessão, mesmo sentindo dores nas articulações dos membros inferiores, a ocupar o centro da roda e arriscar um miudinho? E a senhora que, sem conhecê-la, adentra o espaço do samba portando uma muleta para dançar e cumprimentá-la? As respostas possivelmente passam também por relações emocionais e sociais, nas quais estão inclusos o respeito a si mesmo, ao outro, à ancestralidade, à memória dos antepassados. Passam pelo desejo de ser feliz. Então, mesmo impossibilitada de sapatear como sabe fazer, D. Dalva deixa-se fluir de forma mais controlada, brinca com os ombros, com os quadris e continua encantando os presentes. Sapateia, sambadeira, sapateia, sapatear

Outro aspecto que chamo atenção aqui é a "dança" dos pés das mulheres no samba de roda, embora elas não reconheçam esse termo: ouvi de muitas delas que "dança é dança e samba é samba" e que a sambadeira não dança, ela sapateia. Quando as 12 mulheres do samba de roda que entrevistei foram questionadas sobre o que é ser uma boa sambadeira, algumas respostas surgiram como "ser companheira", "conhecer e respeitar as regras do samba", "participar das atividades do samba", "ser solidária", "sambar e falar a linguagem do samba de roda", mas todas elas foram unânimes em dizer que a boa sambadeira, mesmo, é aquela que tem "o sapateado nos pés, que sabe pinicar o pé, arrastar o pé no chão", como diz D. Rita da Barquinha, ou "amassar o barro", como costumam dizer D. Zélia do Prato e D. Nicinha.

Observando a importância do sapateado dos pés, a dançarina, professora e pesquisadora Dra. Daniela Amoroso - na sua tese de doutorado, na qual aborda os sambas nas cidades de Cachoeira e São Félix - realizou um estudo cuidadoso do miudinho, como se costuma chamar esse sapateado. Suas pesquisas acerca das danças populares levaram-na a concluir que o "passo" é aquilo que identifica uma determinada dança tradicional e que permite a transgressão das fronteiras entre o patrimônio imaterial e material, entre o tempo e o espaço. Refere-se ao miudinho como um princípio de movimento advindo da diáspora africana e que 
se configura no samba de roda e chama a atenção para um detalhe importante que vamos observar com frequência no sapateado, que é a divisão rítmica do passo - ternária - que difere da dos instrumentos percussivos - binária. (AMOROSO, 2019)

Assim como Amoroso, para analisar o(s) sapateado(s) do Recôncavo, parti das minhas próprias experiências corporais que são bastante imbricadas com o samba de roda. Comparando minhas formas de pisar o solo no samba, experimentando o sapateado de minha mãe, que sambava de um jeito singular e que nunca vi nada semelhante em outra mulher, vendo as diversas sambadeiras, buscando imitá-las, percebo que o miudinho não é único. São várias as formas de mover-se ritmicamente no samba, quase sem tirar os pés do chão, embora muitas delas se assemelhem.

Ciente dessa diversidade, solicitei às sambadeiras entrevistadas para esta pesquisa que sambassem sem música e, assim, pude obter o som dos ritmos que produziam com os pés. Com esse material gravado em vídeo, juntei-me aos percussionistas Sebastian Notini e Bira e juntos analisamos as imagens de oito dessas 13 sambadeiras e também outros vídeos, com elas em performance com música, visto que ambos elementos, dança e música, são complementares e dialogam entre si no samba de roda. Sebastian e eu transcrevemos os ritmos produzidos pelos pés delas para notação musical, cientes que esta ferramenta de escrita não tem elementos suficientes para traduzir todo o rico universo da música popular brasileira e, mais ainda, tratando-se de um ritmo de dança. Contudo, analisar as imagens com e sem a orquestra musical e tentar transpor isso para uma escrita rítmica musical nos deu a dimensão da relação íntima entre corpo e som, entre o movimento e as claves do pandeiro, do prato e faca e, sobretudo, da viola.

A notação musical nos trouxe também uma visualização da similaridade e também da diversidade dos desenhos rítmicos que as mulheres executam. Entre as oito sambadeiras analisadas, seis delas executam, em algum momento, um sapateado bastante similar entre si. Por outro lado, D. Nicinha, de Santo Amaro, e Any Manuela, de Cachoeira, mostram uma diversidade muito grande na execução dos seus passos. A primeira praticamente arrasta os pés pelo solo e é muito difícil decodificar o que ela faz, pois quase nunca repete o sapateado, desloca-se muito no espaço, gira, improvisa, faz quebradas rítmicas no tempo. Any Manuela, por sua vez, tem um caminhar mais claro e com repetições, porém também usa bastante o recurso de improviso e de quebradas fora de uma métrica padrão de tempo.

O estudo da rítmica do sapateado me levou à conclusão de que a alternância rítmica entre um pé e o outro é o que caracteriza todos os miudinhos analisados, porém difere de acordo com o estilo praticado pela comunidade de samba ou pela própria sambadeira. 
Entre as sambadeiras observadas, D. Biu faz outro tipo de sapateado que difere totalmente do miudinho. Os sambadores e sambadeiras da sua localidade o chamam de cortajaca. O passo consiste em, mantendo como base o pé esquerdo completamente apoiado no solo, o pé direito dá repetidos golpes no chão como se quisesse cortar algo (no caso, a jaca). Depois desses golpes, ainda mantendo a mesma base, o pé direito passa pela frente do outro e vai para o lado esquerdo e retorna para o local de origem, como se alisasse o chão, que significa tirar o "bagunço da jaca", ou seja, tirar o miolo, a parte comestível dessa fruta.

Em realidade, o passo que ela mostra como corta-jaca é o mesmo que conhecemos com o nome de xaxado, tão popular em todo o Nordeste brasileiro. O baticum que ela pede a atenção para que eu perceba é exatamente o desenho rítmico que a zabumba faz quando se toca o xaxado. Isso nos fornece indícios de diálogos entre as manifestações populares nordestinas. D. Biu conta que aprendeu o passo com sua mãe - Dona Nita - que nasceu em Olinda, em Pernambuco, mesmo Estado do cantor e compositor Luiz Gonzaga, que tanto divulgou esse ritmo, cuja origem está associada a uma dança praticada no Alto Sertão de Pernambuco, executada por pessoas do sexo masculino que, sem instrumentos musicais, cantavam e marcavam o ritmo batendo no chão com rifles ${ }^{11}$. A palavra xaxado, por sua vez, vem de "xaxar", o que significava para o sertanejo retirar o caroço do feijão da vagem batendo nele com um pau.

É possível que D. Nita, ao mudar-se de Olinda para o município de São Francisco do Conde (BA), tenha trazido na sua bagagem sua vivência com o xaxado na localidade onde viveu ou, ainda na Bahia, tenha conhecido a dança da "moda" na ocasião. O fato é que na sua dança o ritmo pernambucano aparece associado com o samba chula baiano numa combinação precisa e bastante singular. Parece-me provável que ela tenha criado o seu próprio corta-jaca. Sua filha herdou esse seu saber e o preserva com muito respeito e orgulho. E, com muita desenvoltura, continua a difundi-lo nas apresentações públicas do grupo Raízes de Angola, do qual faz parte.

Assim como os sapateados das outras sambadeiras, o desenho rítmico do xaxado apresentado aqui em notação musical não pode ser visto como se o seu desenrolar na cena do samba seja algo ensaiado e nem matemático. As sambadeiras variam os desenhos rítmicos/espaciais dos pés na roda dentro do que percebem e sentem da música. À medida que

\footnotetext{
11 SILVA E BRITO (2012), em artigo publicado nos anais do III Congresso Internacional de História da UFG/ Jataí: História e Diversidade Cultural, relacionam o surgimento do xaxado no período do cangaço e a sua difusão para outros Estados do Nordeste pelo bando de Lampião. Disponível em: $<$ http://www.congressohistoriajatai.org/anais2012/Link\%20(48).pdf>
} 
elas "atendem" aos chamados dos tocadores, modificam seus sapateados. Então, para pensarmos as falas das mulheres, trazidas em parágrafos anteriores, sobre o sapateado dos pés ser algo determinante para que uma sambadeira seja considerada boa no que faz, precisamos atentar para outros fatores que entram em jogo, como os acasos que podem ocorrer e a "presença e a percepção do momento, que depende da sabedoria e experiência de cada mulher de se entregar ao prazer, ao mesmo tempo mantendo o controle da situação e do diálogo da 'conversa' com músicos e participantes. " (DÖRING, 2016, p. 124). É preciso atentar ainda em que os pés sapateando enquanto se movem no espaço, seja andando para frente, para trás, de lado ou em giros, são apenas os detonadores de um mover que envolve todo o corpo.

\section{Considerações finais}

A cena do samba de roda foi aqui brevemente analisada a partir da referência corporal de mulheres sambadeiras que cresceram e viveram tendo o samba como parte do cotidiano. $\hat{E}$ preciso ressaltar que as configurações, que hoje se observam nas comunidades de samba, muitas vezes diferem das vividas por elas algumas décadas atrás. Embora atento a essas mudanças, este trabalho se reporta, prioritariamente, àquelas configurações que estão na memória das mais antigas, cujos trabalhos têm sido importantes para a preservação e reativação de tradições que estavam quase adormecidas por diversos fatores, e que vêm recebendo novo vigor nos últimos 15 anos.

Adentrando na cena do samba com esse referencial, saio dela com o entendimento de que a roda onde acontecem os comportamentos cênicos é, ela mesma, também um destes. Um comportamento que envolve uma relação ancestral étnica, imbuída de valores comunitários, que se deseja serem respeitados. Compreendo a roda, portanto, não somente como uma configuração espacial circular. Além dos procedimentos que ocorrem nela, que estão de acordo com aqueles estabelecidos pelos antepassados de seus praticantes, também a história de cada pessoa que nela adentra vai estar expressa no corpo em movimento.

O desejo da participação festiva é o que parece mover os sambadores e sambadeiras. A roda é o local da materialização daquilo que as capacidades perceptivas absorvem das camadas sonoras do samba, e de alguma forma fazem brotar um sentimento de alegria, que se comunga comunitariamente. O samba se ergue como efeito da aglutinação de saberes dos antepassados, que foram configurados para proporcionar prazer. E observo que esses saberes se territorializam na roda. 
Entre eles está o "saber-dançar". E para compreendê-lo, busquei o entendimento: do equilíbrio do corpo nos vários sapateados das sambadeiras; na análise das atitudes corporais, a partir dos fatores do movimento; do estudo rítmico dos sapateados dos pés, na execução do passo característico do samba, o miudinho, e do corta-jaca, também encontrado na região do Recôncavo. O estudo da rítmica do sapateado de algumas sambadeiras e a posterior transcrição para notação musical apontaram para a inexistência de um padrão único do miudinho.

Pondero, entretanto, que as transcrições rítmicas dos passos das sambadeiras são apenas referências, que podem ajudar no entendimento das similaridades e diferenças existentes entre o que elas realizam ao sapatearem, assim como auxiliar na iniciação do aprendizado deles, mas nem de longe abrange as múltiplas conexões corporais que estão no entorno desse sapateado.

Nestas últimas considerações, ressalto que é importante o reconhecimento da existência de espaços de sociabilidades, celebração e afetividade entre os povos negros que, subjugados em sua condição de escravizados, assistiram também sobre si ao esvaziamento destas subjetividades, portanto, corroborando para manter incrementados os elementos de coisificação de suas existências.

Esta pesquisa me revelou ainda que, embora os homens assumam um papel central na produção musical do samba de roda, são as mulheres os pilares da ligação afetiva, familiar e comunitária que sempre manteve o samba de roda vivo. A atuação delas é fundamental para a manutenção desse patrimônio imaterial que tanto lhes é caro, onde o corpo se manifesta numa dinâmica de trocas, relações e diálogos.

\section{FONTES}

\section{Fontes primárias}

\section{Entrevistas:}

CRUZ, Milton José Primo da (Milton Primo). Residência de Milton Primo, São Francisco do Conde, 03.out. 2018. 1 h36min.

SOUZA, Zélia Maria Paiva (D. Zélia do Prato). Residência de D. Zélia do Prato, São Braz (Santo Amaro). 27.jul.2018. $56 \mathrm{~min}$.

\section{REFERÊNCIAS}


AJAYI, Omofolabo S. Yoruba Dance: The semiotics of Movement and boby attitudein a Nigerian Culture. Trenton: Africa World Press, 1998.

AMOROSO, Daniela M. Levanta mulher e corre a roda: dança, estética e diversidade no samba de roda de São Félix e Cachoeira. 2009. Tese (Doutorado) - Escola de Teatro/Escola de Dança, Universidade Federal da Bahia, Salvador, 2009.

ASANTE, Kariamu W. (org.). African Dance: an Artistic, Historical and Philosophical Inquiry. 3.ed. Trenton: Africa World Press, 2002.

BARBA, Eugene; SAVAREZE, Nicolas. A arte secreta do ator: um dicionário de Antropologia Teatral. São Paulo: Corprint Gráfica e Editora, 2012

BIÃO, Armindo. Etnocenologia e a cena baiana: textos reunidos. Salvador: P\&A Gráfica e Editora, 2009.

BOMFIM, Vânia M. S. A identidade contraditória da mulher negra brasileira: Bases históricas. In: NASCIMENTO, Elisa L. N. (Org.). Afrocentricidade: uma abordagem epistemológica inovadora. São Paulo: Selo Negro, 2009.

CARNEIRO, Sueli. Enegrecer o feminismo: a situação da mulher negra na América Latina a partir de uma perspectiva de gênero. Geledes, São Paulo, 6.mar.2011. Disponível em: $<$ https://www.geledes.org.br/enegrecer-o-feminismo-situacao-da-mulher-negra-na-america-latina-partir-deuma-perspectiva-de-genero/>. Acesso em: 18.fev.2018.

DOMENICl, Eloísa. O corpo no samba chula do litoral norte da Bahia e suas possíveis contribuições para o artista cênico. Anais da VI Reunião do ABRACE. Porto Alegre: ABRACE, 2011.

DÖRING, Katharina. A Cartilha do samba chula. Salvador: Natura Musical, 2016.

GOMES, F.; ROSA, L. Os processos de protagonismo de mulheres negras no recôncavo da Bahia: O samba de roda como mediador das relações cotidianas. Revista Olhares Sociais/PPPG/UFRB, v.2, 2014. Disponível em: $\quad<$ https://www3.ufrb.edu.br/olharessociais/wp-content/uploads/6-Especial-OS-PROCESSOS-DEPROTAGONISMO-DE-MULHERES-NEGRAS-NO-RECONCAVO-DA-BAHIA ok final 01.pdf> Acesso em: 13.mar.2019.

GOMES, Rodrigo Cantos Savelli. Samba no feminino. Transformações das relações de gênero no samba carioca nas três primeiras décadas do século XX. 2011. 157f. Dissertação (Mestrado em Música, Musicologia e Etnomusicologia) - Universidade do Estado de Santa Catarina, Florianópolis, 2011.

LABAN, Rudolf. Domínio do Movimento. São Paulo: Sumos, 1978.

LE BRETON, David. Antropologia do Corpo e Modernidade. Petrópolis: Vozes, 2013.

MARTINS, Leda M. Afrografias da Memória: O Reinado do Rosário no Jatobá. Belo Horizonte: Mazza Editora Ltda., 1997.

MCCLARY, Susan. Feminine Endings: Music, Gender and Sexuality. Minnesota: University of Minnesota 1991. 
MCCLARY, Susan; WALSER, Robert. Theorizing the body in African-American Music. Black Music Research Journal, v. 14, n.1, 1994, pp. 75-84. Disponível em: <http://www.hugoribeiro.com.br/bibliotecadigital/McClary Walser-Theorizing body.pdf> Accesso: 11.abr.2018.

PRADIER, Jean-Marie. In: GREINER, Christine; BIÃO, Armindo (org). Etnocenologia: textos selecionados. São Paulo: Annsblume, 1999, p. 23-29.

PRIMUS, Pearl. African Dance. In: ASANTE, Kariamu W. (org.). African Dance: an Artistic, Historical and Philosophical Inquiry. 3.ed. Trenton: Africa World Press, 2002.

RENGEL, Lenira. Os temas de movimento de Rudolf Laban ( I - II - III - IV - V - VI - VII - VIII): modos de aplicação e referências. São Paulo: Anablume, 2008.

SABINO, Jorge; LODY, Raul. Danças de Matriz Africana: Antropologia do Movimento. Rio de Janeiro: Pallas, 2011

SANTOS, Inaicyra. Corpo e Ancestralidade: Uma proposta pluricultural de dança-arte-educação. São Paulo: Terceira Margem, 2006.

SILVA, Amanda; BRITO, Eleonora. Xaxado: a construção da identidade e da memória social do Cangaço. In: CONGRESSO INTERNACIONAL DE HISTÓRIA DA UFG, 3, 2012, Jataí. Textos Completos... Jatai: UFG, 2012.

SODRÉ, Muniz. Samba, o dono do corpo. 2a. ed. Rio de Janeiro: Mauad Editora Ltda., 1998. 